\title{
Effects of sexual dimorphism on population parameters and exploitation ratios of blue marlin (Makaira nigricans) in the northwest Pacific Ocean
}

\author{
Nan-Jay Su ${ }^{1}$, Chi-Lu Sun ${ }^{1}$, a , André E. PunT ${ }^{2}$, Su-Zan YeH$^{1}$, Wei-Chuan ChiAng ${ }^{3}$, Yi-Jay Chang ${ }^{1}$ \\ and Hsiao-Yun CHANG ${ }^{1}$ \\ 1 Institute of Oceanography, National Taiwan University, Taipei, 10617 Taiwan \\ 2 School of Aquatic and Fishery Sciences, University of Washington, Seattle, WA 98195, USA \\ ${ }^{3}$ Eastern Marine Biology Research Center, Fisheries Research Institute, Taitung, 96143 Taiwan
}

Received 19 August 2012; Accepted 21 November 2012

\begin{abstract}
Blue marlin are sexually dimorphic in size-at-age and other biological characteristics. However, few studies have examined the possible impact of sexual dimorphism on the population parameters and the ratios of fishing to total mortality (the exploitation ratios) for this species. We analyzed sex-specific catch-at-length data for blue marlin collected from the Taiwanese tuna longline fishery in the northwest Pacific Ocean, ranging between 100-311 cm in eye to fork length (EFL) for females and 100-236 cm EFL for males, and show that the proportion of females in the catch (the sex ratio) increases with length, with females reaching larger body sizes than males. Minor differences in fishery sex ratios among months were observed. Growth parameters, length structures, and natural mortality rates were estimated to differ between males and females, while fishing mortality rates were found to be similar. Nevertheless, the exploitation ratio for females was higher than that for males. We suggest that growth parameters and natural mortality rates should be sex-specific when assessments for sexually-dimorphic species such as blue marlin are conducted, and that management of blue marlin fisheries could be developed based on size limit regulations for large individuals.
\end{abstract}

Keywords: Sex-specific size data / Sex ratio / Length structure / Growth parameter / Mortality rate / Billfish / Istiophoridae

\section{Introduction}

Blue marlin (Makaira nigricans Lacepede 1802) is a cosmopolitan species distributed throughout tropical, subtropical, and temperate waters of the Indo-Pacific and Atlantic Oceans between $45^{\circ} \mathrm{N}$ and $45^{\circ} \mathrm{S}$ (Su et al. 2011a). Most blue marlin are caught, as an incidental bycatch of considerable economic value, by longline vessels targeting tunas, while small catches of blue marlin are taken using surface gears, such as gillnets and harpoons, as well as by recreational, purse seine, and baitboat fisheries (Hinton 2001). In the Pacific Ocean, the annual catches of blue marlin usually exceed those of swordfish and those of other billfishes combined (Molony 2008).

A single stock of blue marlin in the Pacific Ocean has been assumed based on analyses of genetic divergence (Graves and McDowell 2003) and fishery catch-rates (Kleiber et al. 2003). The assumption of a single stock is also supported by the results of tagging experiments, which have shown that blue

a Corresponding author: chilu@ntu.edu.tw marlin migrate long distances, up to more than $8000 \mathrm{~km}$ in some instances (Hinton 2001).

Blue marlin are the largest of the billfishes, and are the most popular gamefish because of their size and fighting ability (Molony 2008). They exhibit sexual dimorphism in size, with males reaching a maximum size of $200 \mathrm{~cm}$ in length while females can grow much larger than males (Wilson et al. 1991). The sizes-at-maturity also differ between males and females (Sun et al. 2009). Several explanations have been proposed to explain this sexual dimorphism, including sex-specific growth and mortality rates (Hill et al. 1989).

Estimates of population parameters provide fundamental information for stock assessments and fishery management (Fry and Griffiths 2010). For example, sex ratios, length structures, and growth parameters could be used as basic inputs in stock assessments (Kleiber et al. 2003). Natural and fishing mortality rates are also necessary to apply per-recruit methods to determine the status of fish populations as well as fishery impacts (Quinn and Deriso 1999). However, previous studies have shown that these parameters are likely to differ between the sexes for blue marlin (Kleiber et al. 2003; Su et al. 2011b). 
Table 1. Conversion equations for eye to fork length (EFL, $\mathrm{cm}$ ), lower jaw to fork length (LJFL, $\mathrm{cm})$, weight ( $W$, $\mathrm{kg}$ ), and sex ratio for blue marlin in the northwest Pacific Ocean.

\begin{tabular}{lcccc}
\hline Equation & Sex & Coefficients & $r^{2}$ & $n$ \\
\hline LJFL $=a+b$ EFL & Pooled & $a=9.550 ; b=1.080$ & 0.986 & 312 \\
$W=c \mathrm{EFL}^{\mathrm{d}}$ & Female & $c=1.427 \times 10^{-5} ; d=2.996$ & 0.878 & 717 \\
\multirow{2}{*}{ Sex ratio $=1 /\left[1+e^{s\left(\mathrm{EFL}-L_{0.5}\right)}\right]$} & Male & $c=1.116 \times 10^{-5} ; d=3.033$ & 0.871 & 1043 \\
& - & $s=0.123 ; L_{0.5}=178.546$ & 0.983 & 27 \\
\hline
\end{tabular}

$n$ denotes the sample sizes used to fit the equations.

The relationship between sex ratio and length is based on fish of larger than $150 \mathrm{~cm} \mathrm{EFL}$.

The objectives of this study were: 1) to estimate the life history parameters of blue marlin by sex that are poorly described in previous studies, 2) to examine the effect of sexual dimorphism on population parameters and exploitation ratios, and 3) to provide suggestions for how the population dynamics of sexually-dimorphic species should be modeled when assessments are conducted.

\section{Materials and methods}

Eye to fork length (EFL, in $\mathrm{cm}$ ), lower jaw to fork length (LJFL, in $\mathrm{cm}$ ), whole weight ( $W$, in $\mathrm{kg}$ ), and sex information for blue marlin caught in the northwest Pacific Ocean (Fig. 1) by Taiwanese small-scale ( $<100$ gross register tons) tuna longline vessels were collected monthly and randomly at the fishing ports during 2000 to 2006. Sex was identified by examining the gonads. EFL measurements were used in this study because LJFL and $W$ data were not available for all sampled animals because fishers removed the bills and jaws of some blue marlin at sea. EFL-LJFL (LJFL $=a+b$ EFL) and EFL$W\left(W=c \mathrm{EFL}^{\mathrm{d}}\right)$ relationships were derived 1) to test, using analysis of covariance (ANCOVA), for differences between the sexes and 2) to make conversions between different measurements if there was a need for this (Table 1).

The sex ratio was defined as the ratio of the number of females to the total number of animals. The sex-ratio data by length were used to fit the logistic equation: sex ratio $=$ $1 /\left[1+\mathrm{e}^{s\left(\mathrm{EFL}-L_{0.5}\right)}\right]$, where $s$ is the slope of the curve and $L_{0.5}$ is the length at which the probability of occurrence of females is equal to that of males. The data points for lengths below $150 \mathrm{~cm}$ EFL were ignored when fitting this equation following Wang et al. (2006) because different trends in sex-ratio with length were observed for animals smaller than $150 \mathrm{~cm}$. Monthly sex ratios, aggregated over years, were analyzed using the Chi-square $\left(\chi^{2}\right)$ test to identify seasonal effects and whether sex-ratios differed from 0.5 .

The Shannon diversity index (Shannon 1948): $H=$ $-\Sigma p_{i} \log p_{i}$, where $p_{i}$ is the proportion of fish in length class $i$, was used to summarize the diversity of the catch length structure (Ottersen et al. 2006). The $H$ values were calculated by sex and month to evaluate the impact of sexual dimorphism, and to examine seasonal variation in length distributions. The $\chi^{2}$ test was selected to test for sex-specific differences in length structures.

The growth of many billfish species is hard to determine because interpretation of annuli is complicated due to the

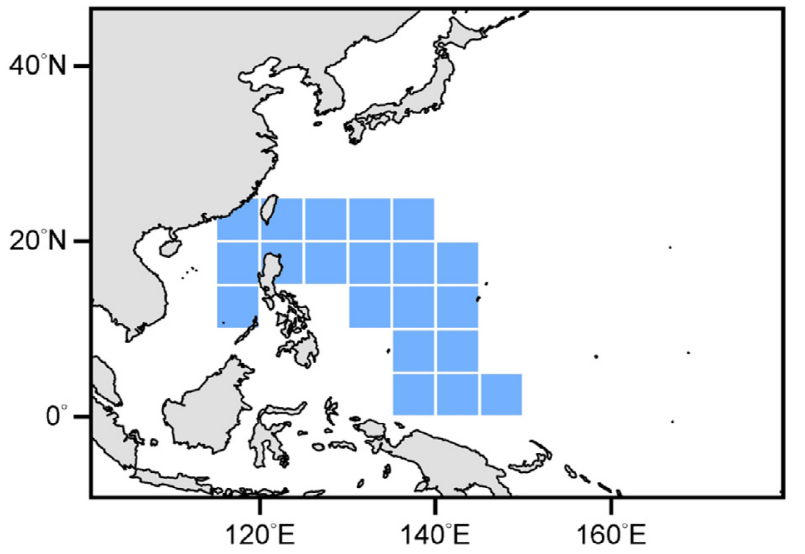

Fig. 1. Map of the northwest Pacific Ocean showing the area where blue marlin were caught based on logbooks.

presence of non-age related bands (false checks) and vascularization in the fin-spine core (Kopf et al. 2010). The parameters by sex of the von Bertalanffy growth equation (VBGE) were therefore estimated using empirical equations. The asymptotic length $\left(L_{\text {inf }}\right)$ that the fish would eventually attain should not differ too much from the average of the maximum sizes among individuals (Froese and Binohlan 2000). The equation developed by Froese and Binohlan (2000) was used therefore to estimate $L_{\text {inf }}$, based on the length of the largest fish sampled from the population $\left(L_{\max }\right)$. The growth coefficient $(K)$ can be estimated using Beverton's (1992) equation, which relates $K, L_{\text {inf }}$, the length-at-first-maturity $\left(L_{\mathrm{m}}\right)$, and the mean age-at-first maturity $\left(t_{\mathrm{m}}\right)$. The equations and the values used in this study are summarized in Table 2.

Two methods were used to estimate total and natural mortality $(Z$ and $M)$ under the assumption that the population is in equilibrium with respect to fishing and natural mortality.

(1) A length-converted catch curve (Pauly 1983): $\ln \left(N_{i} / \Delta t_{i}\right)=$ intercept $-Z_{1} t_{i}$, where $N_{i}$ is the number of fish in length class $i, \Delta t_{i}$ is the time required to grow through length class $i$, and $t_{i}$ is the relative age corresponding to the midpoint of length class $i$.

(2) The approach of Beverton and Holt (1956), which relates total mortality to $L_{\text {inf }}, K$, the mean length in the catch $\left(L_{\mu}\right)$, and the length-at-first capture $\left(L_{\mathrm{c}}\right): Z_{2}=K\left(L_{\text {inf }}-L_{\mu}\right) /\left(L_{\mu}-\right.$ $\left.L_{\mathrm{c}}\right) . L_{\mathrm{c}}$ is often chosen in practice as the length with the highest catch (Thorson and Prager 2011). 
Table 2. Estimates of population parameters for blue marlin in the northwest Pacific Ocean and the equations used to estimate them (see Sect. 2 for the definitions of the symbols). Fish length: eye to fork length (EFL).

\begin{tabular}{|c|c|c|c|c|}
\hline Parameter & Female & Male & Equation & Reference \\
\hline$L_{\mathrm{c}}(\mathrm{cm})$ & 193 & 153 & & This study \\
\hline$L_{\mu}(\mathrm{cm})$ & 211 & 168 & & This study \\
\hline$L_{\max }(\mathrm{cm})$ & 311 & 236 & & This study \\
\hline$L_{\mathrm{m}}(\mathrm{cm})$ & 158 & 131 & & Sun et al. 2009 \\
\hline$t_{\mathrm{m}}($ year $)$ & 4 & 3 & & Molony 2008 \\
\hline$L_{\text {inf }}(\mathrm{cm})$ & 314 & 239 & $10^{0.044+0.984 \log \left(L_{\max }\right)}$ & Froese and Binohlan 2000 \\
\hline$K\left(\right.$ year $\left.^{-1}\right)$ & 0.10 & 0.15 & $\ln \left(1+L_{\mathrm{m}} / L_{\mathrm{inf}}\right) / t_{\mathrm{m}}$ & Beverton 1992 \\
\hline$Z_{1}\left(\right.$ year $\left.^{-1}\right)$ & 0.59 & 0.66 & $\ln \left(N / \Delta t_{i}\right)=$ intercept $-Z_{1} t_{i}$ & Pauly 1983 \\
\hline$Z_{2}\left(\right.$ year $\left.^{-1}\right)$ & 0.58 & 0.66 & $K\left(L_{\mathrm{inf}}-L_{\mu}\right) /\left(L_{\mu}-L_{\mathrm{c}}\right)$ & Beverton and Holt 1956 \\
\hline$M_{1}\left(\right.$ year $\left.^{-1}\right)$ & 0.20 & 0.27 & $\mathrm{e}^{-0.015-0.279 \ln \left(L_{\text {inf }}\right)+0.654 \ln (K)+0.463 \ln (T)}$ & Pauly 1980 \\
\hline$M_{2}\left(\right.$ year $\left.^{-1}\right)$ & 0.16 & 0.23 & $1.6 \mathrm{~K}$ & Jensen 1996 \\
\hline$F\left(\right.$ year $\left.^{-1}\right)$ & $0.38-0.43$ & $0.39-0.43$ & $Z-M$ & \\
\hline$E$ & $0.66-0.72$ & $0.59-0.65$ & $F / Z$ & \\
\hline
\end{tabular}

A mean temperature of $26^{\circ} \mathrm{C}$ (Pine et al. 2008) was used when applying Pauly's (1980) method.

Natural mortality was estimated using the empirical relationships of Pauly (1980) and Jensen (1996) (Table 2). These different approaches for $Z$ and $M$ were applied to examine the sensitivity of the estimates to the method of estimation. Fishing mortality $(F)$ was then estimated by subtracting the estimate of $M$ from that of $Z$ and was used to estimate the exploitation ratio (i.e., $E=F / Z$ ).

\section{Results}

In total, 1325 female and 1943 male blue marlin were sampled, with mean lengths of $193 \mathrm{~cm}$ and $158 \mathrm{~cm}$ EFL, respectively (Fig. 2). The EFL-LJFL equations by sex were pooled because the sex-specific relationships did not differ statistically (ANCOVA, $p>0.05$ ) (Fig. 3; Table 1). However, the relationships between EFL and $\mathrm{W}$ differed significantly between the sexes (ANCOVA, $p<0.01$ ) so separate relationships are reported in Table 1 (Fig. 4).

The overall sex ratio of sampled blue marlin was 0.41 $(n=3268)$, suggesting that males are more frequent than females in catches of blue marlin by the Taiwanese longline fishery ( $\chi^{2}$ test, $\left.p<0.05\right)$. However, the sex ratios vary seasonally (Fig. 5). For example, the sex ratios for November and December are higher than $0.41\left(\chi^{2}\right.$ test, $\left.p<0.05\right)$, while those in the other months were close to 0.41 ( $\chi^{2}$ test, $\left.p>0.05\right)$, except for August $\left(\chi^{2}\right.$ test, $\left.p>0.05\right)$. The relationship between sex ratio and length clearly indicates the sexual dimorphism of blue marlin (Fig. 6; Table 1). All fish of length larger than $240 \mathrm{~cm}$ EFL are identified as females.

Most female blue marlin sampled from the longline fisheries were between 190 and $210 \mathrm{~cm}$ EFL (Fig. 7a). In contrast, the males tended to be between 150 to $170 \mathrm{~cm}$ EFL (Fig. 7b). The mean lengths varied among months for both sexes (ANOVA; $p<0.01$ ) with less variation for males (155 to $165 \mathrm{~cm}$ EFL), than for females (174 to $206 \mathrm{~cm}$ EFL). The Shannon diversity index indicates seasonal variation and different length structures of size samples between females and males (1.331 and 1.112 respectively; $\chi^{2}$ test, $p<0.01$;

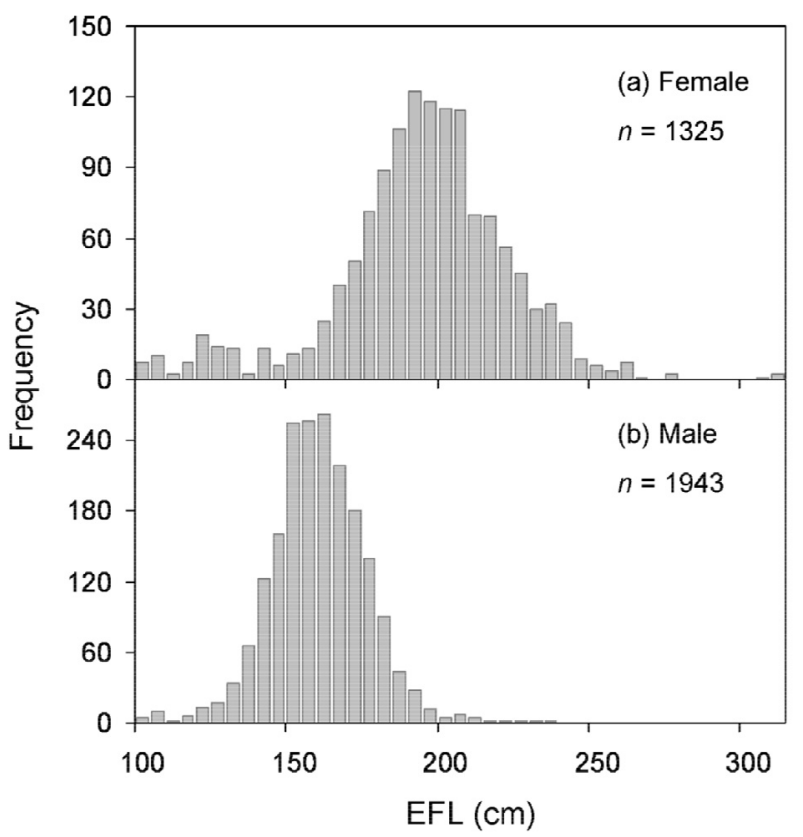

Fig. 2. Length-frequency distributions for blue marlin captured by the Taiwanese tuna longline vessels in the northwest Pacific Ocean.

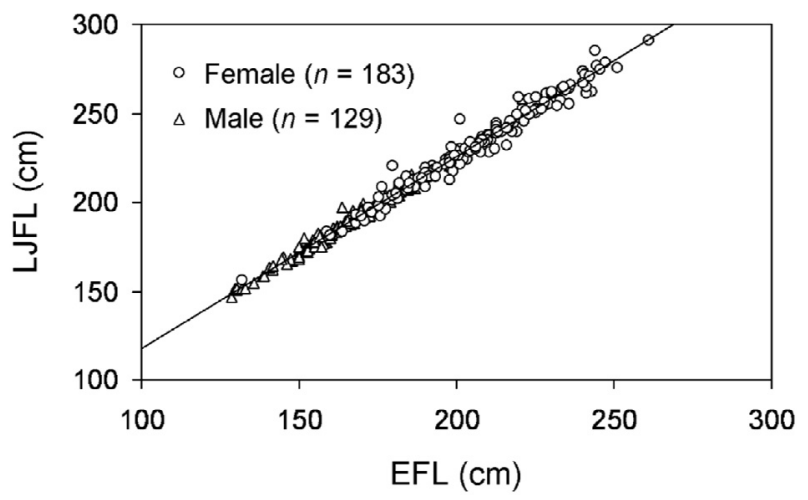

Fig. 3. The relationship between eye to fork length (EFL) and lower jaw to fork length (LJFL) for blue marlin in the northwest Pacific Ocean (sex-pooled; ANCOVA, $p>0.05$ ). 


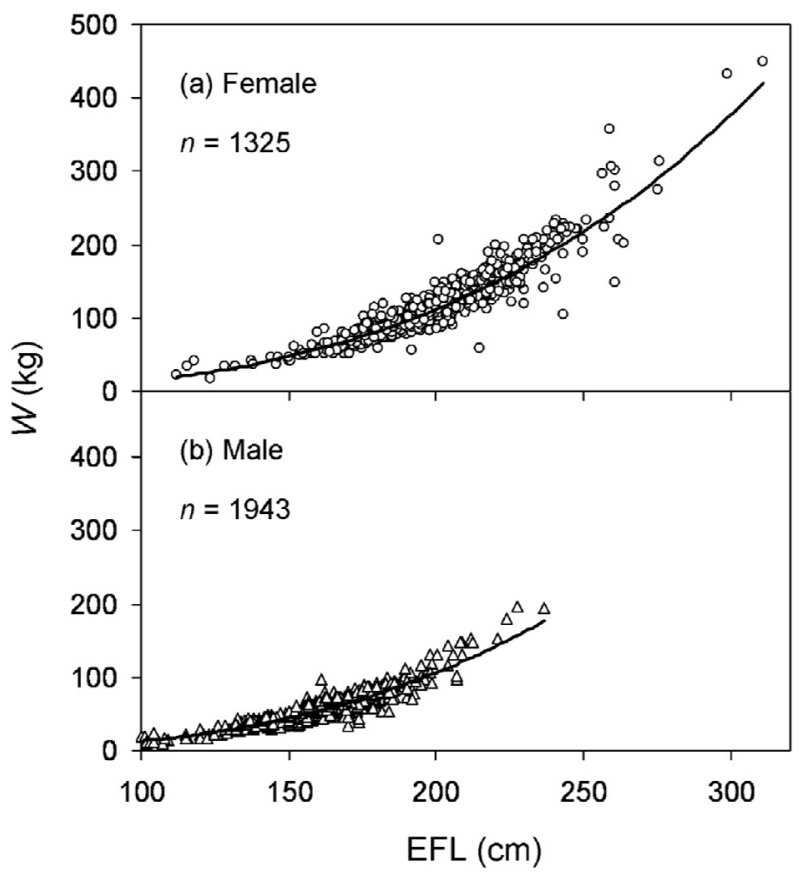

Fig. 4. Relationships between eye to fork length (EFL) and weight $(W)$ for blue marlin in the northwest Pacific Ocean.

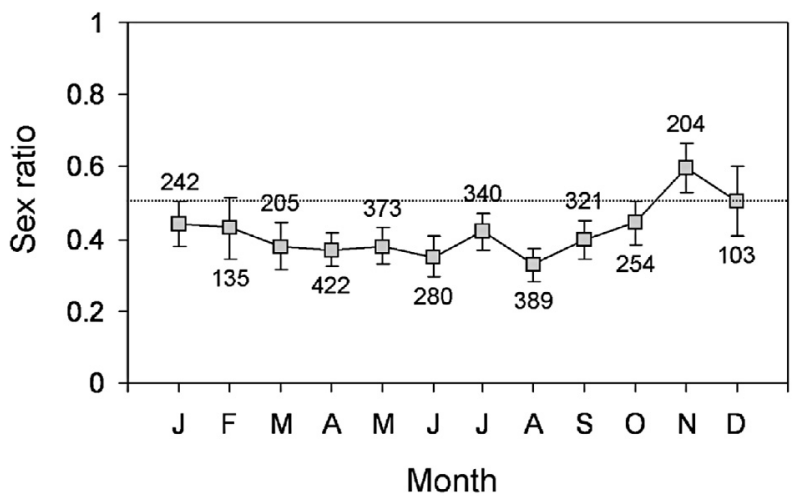

Fig. 5. Monthly sex ratios (the proportion of females) of blue marlin in the northwest Pacific Ocean. The numbers above symbols are sample sizes. Vertical bars represent two standard errors. The dotted line indicates the sex ratio of 0.5 .

Fig. 7). The catch-at-size data differ among months for most the months ( $\chi^{2}$ test, $p<0.05$ ).

The estimates of the VBGE parameters are listed in Table 2. The estimates of $L_{\text {inf }}$ and $K$, as expected, differ between the sexes. The relative ages at which fishes are fully recruited, selected based on the size at which catch-at-length is maximized (Fig. 2), varied between males and females (Fig. 8). The estimates of $Z$ from the two methods differ between the sexes (Table 2; Fig. 8) while the estimates for $M$ differ between the sexes and between the methods (Table 2). The estimated fishing mortality rates are similar between the sexes, but the lower estimates of $M$ for females mean that the exploitation ratio is higher for females than for males (Table 2).

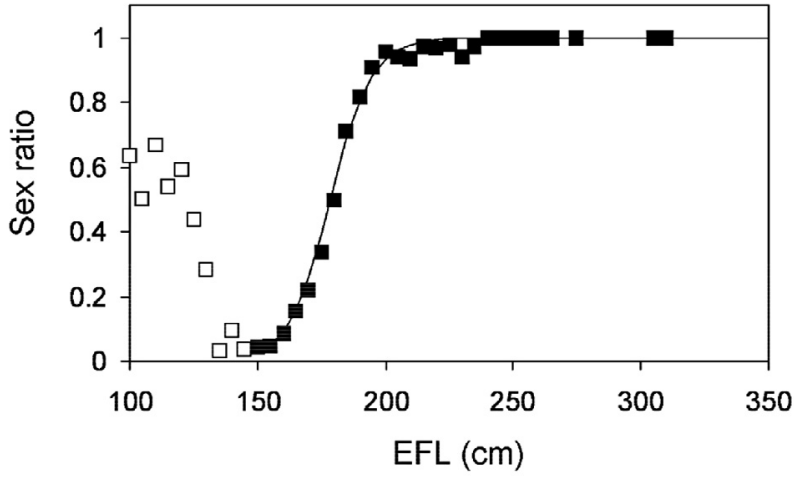

Fig. 6. Observed sex ratios (the proportion of females, squares) by length, and the fitted ogive (lines) based on fish larger than $150 \mathrm{~cm}$ EFL. Solid squares: data used in the regression; open squares: data excluded from the regression.

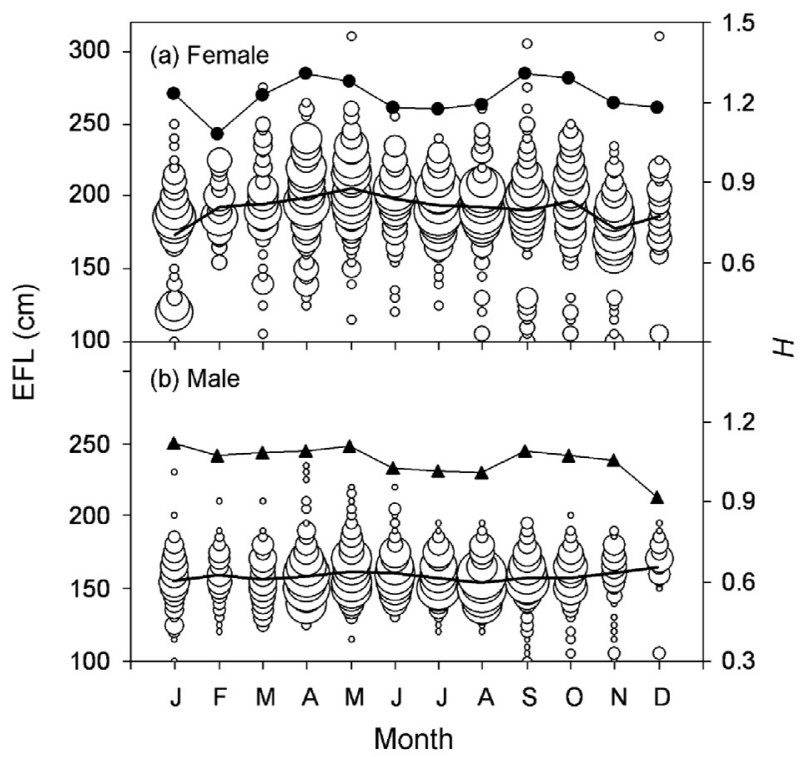

Fig. 7. Monthly length-frequency distributions (open circles), mean lengths (lines), and Shannon diversity indices (lines with solid dots) for blue marlin in the northwest Pacific Ocean.

\section{Discussion}

Data from port sampling are less than ideal for the estimation of population parameters. For example, small fish might be discarded by fishermen at sea. However, although a bycatch species, most blue marlin, including juveniles, are retained by fishers. Blue marlin are also caught in the coastal gillnet, trolling, and harpoon fisheries off Taiwan. However, these fisheries, unlike longline fisheries that operate throughout the year, change gears and targets seasonally. Using data collected only from some months of the year could lead to biased estimates of population parameters (Hufnagl et al. 2010). In addition, the catch length structures, and thus the estimates of population parameters, can be influenced by the selectivity of the sampling gear. For example, large animals may not be caught if selectivity is dome-shaped. However, it is generally assumed that longlines lead to asymptotic selectivity for tunas and billfishes (Sun et al. 2002). 


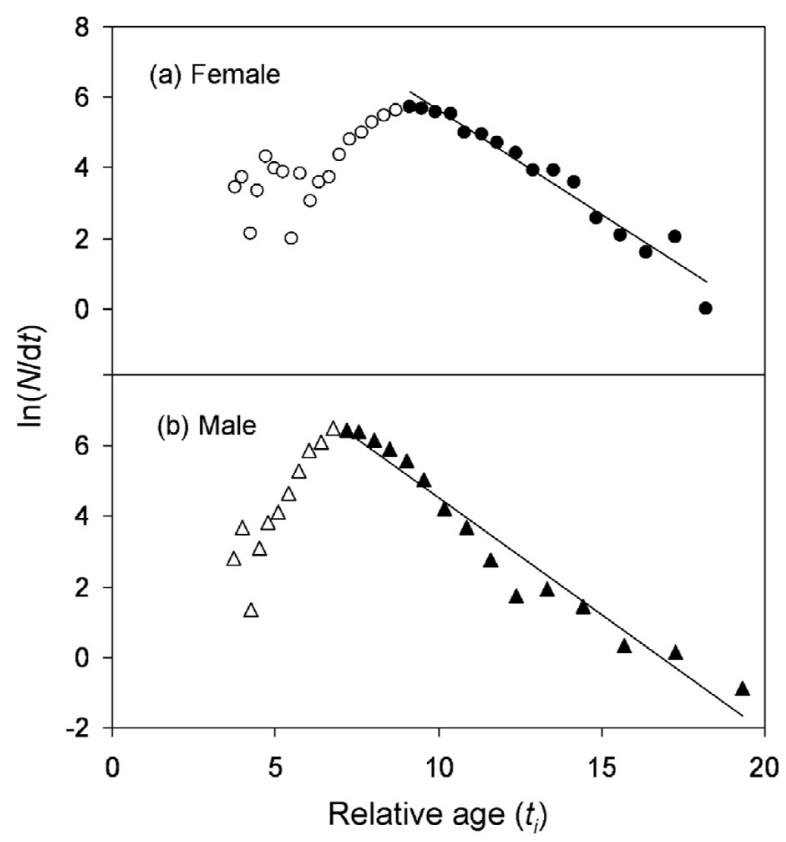

Fig. 8. Length-converted catch curves based on the length-frequency data in Figure 2 and the growth parameters in Table 2. Solid symbols: data included in the regression; open symbols: data excluded from the regression. Females: $\ln \left(N / \Delta t_{i}\right)=11.524-0.591 t_{i}\left(r^{2}=0.956\right.$; $95 \%$ confidence interval for the slope, \pm 0.073$)$; males: $\ln \left(N / \Delta t_{i}\right)=$ $11.130-0.664 t_{i}\left(r^{2}=0.958 ; 95 \%\right.$ confidence interval for the slope, $\pm 0.083)$.

The rapid increase of female proportions with size demonstrates sexual dimorphism in blue marlin (Fig. 6). It is unlikely that male blue marlin grow much larger than those sampled in the Taiwanese tuna longline fishery, given the spatial and temporal coverage of all blue marlin fisheries in the Pacific Ocean (Skillman and Yong 1976; Molony 2008). This pattern, females achieving a larger size than males, occurs in other species of billfishes, such as swordfish (Xiphias gladius), sailfish (Istiophorus platypterus), and black marlin (Makaira indica) (Wang et al. 2006). However, sexual dimorphism in billfishes differs from most other fishes. In many species, including tunas, females invest more energy, compared with males, in maturation, and consequently have lower growth rates and maximum sizes (Schaefer 1996). Many hermaphroditic species also exhibit sexual dimorphism. However, histological analyses indicated that changes in sex do not occur in blue marlin (Sun et al. 2009).

Of the various hypotheses to explain sex-related size differences for blue marlin, sex-specific growth is perhaps the most plausible. Both sexes of blue marlin are equally longlived, reaching ages of more than 20 years, but males reduce somatic growth at about $100 \mathrm{~kg}$ (about $200 \mathrm{~cm}$ EFL) while females keep growing (Wilson et al. 1991). Different migration patterns between the sexes is another hypothesis to explain sexual dimorphism in sizes (e.g., Nakano et al. 2003). For example, large individuals might migrate to spawning or feeding grounds so that they are not available for the fishery at some times of the year. However, very few male blue marlin larger than $200 \mathrm{~cm}$ EFL were observed during the year-round sampling. The sex ratios during the spawning season $(0.35 \sim 0.42$ from May to September; Sun et al. 2009) were close to the overall sex ratio (0.41). However, blue marlin found in an area far from their spawning ground (the Sea of Cortéz) are almost all female, suggesting that females might migrate (GonzálezArmas et al. 2006; Shimose et al. 2012).

The Shannon diversity index is independent of sample size and quantifies a distribution. In this study, $H$ is higher for female blue marlin than for males, implying that sexual dimorphism in size leads to different length structures in landings between the sexes, given equivalent length-based selectivity patterns. Thus, population dynamics models for sexually dimorphic species such as blue marlin should, as previously suggested by Kleiber et al. (2003) and Su et al. (2011b), be fitted to sex-specific catch-at-size data.

Hill et al. (1989) and Wilson et al. (1991) utilized hard parts (i.e., spines and otoliths) to age blue marlin, but neither studies fitted growth curves or estimated growth parameters, although estimated mean lengths-at-age were provided by Hill et al. (1989). Skillman and Yong (1976) applied lengthfrequency analysis to estimate VBGE parameters for blue marlin. However, their estimates were not biologically reasonable, (e.g., an incredibly large estimate, over $1000 \mathrm{~cm}$, for $L_{\text {inf }}$ ). Very few blue marlin larger than $400 \mathrm{~cm}$ were sampled in all commercial and recreational fisheries in the Pacific Ocean (Kleiber et al. 2003; Molony 2008). It would be ideal to age blue marlin within broad size ranges and fit growth curves by sex if this was possible.

It is often difficult to estimate $M$ for exploited fish populations directly (Quinn and Deriso 1999). Therefore, published empirical relationships between $M$ and life history parameters are frequently employed to infer this parameter. However, $M$ and other life history parameters are poorly described by sex for blue marlin. Although the estimated natural mortality rates from the two empirical equations differed, the estimates of natural mortality for females were consistently lower than those for males (Table 2). $M$ should consequently be assumed to differ between sexes when modeling the population dynamics of blue marlin.

A conventional rule of thumb is that the fishing mortality at which maximum sustainable yield (MSY) is achieved equals the natural mortality rate (i.e., $F_{\mathrm{MSY}}=M$ ). However, very few stocks are able to sustain themselves when the exploitation ratio exceeds 0.5 because the spawning stock biomass is reduced substantially (Patterson 1992). Although the optimal fishing mortality rate might vary among species depending on, for example, selectivity, size-at-maturity, and the stock-recruitment relationship, a value for $E$ of 0.5 has been proposed as a target exploitation ratio or a proxy for $F_{\mathrm{MSY}}$ (Rochet and Trenkel 2003). The exploitation ratios for blue marlin are estimated to exceed 0.5 for both sexes, suggesting that this stock and the fisheries using it need to be monitored closely.

It is useful to apply alternative assessment methods when assessing the status of a fish population. The blue marlin stock in the Pacific Ocean has previously been assessed to be overfished or near fully exploited (Kleiber et al. 2003; Su et al. 2012). The results of this study indicate that both sexes of this stock are under high fishing pressure. However, the fishing pressure on females is greater than that on males, which reemphasizes the need to take sexual dimorphism into account 
in stock assessments for sexually-dimorphic species through, for example, the use of sex-specific parameters related to population process such as growth and natural mortality. The management of blue marlin fisheries could be developed based on size limit regulations on larger individuals, particularly for females, to reduce the fishing mortality, if there was a wish.

Acknowledgements. We thank two anonymous reviewers for their thoughtful comments and suggestions. Financial support of this study was partially provided by the National Science Council of Taiwan through grants NSC89-2316-B-002-038, NSC93-2313-B-002-053, and NSC94-2313-B-002-067 to C. L. Sun.

\section{References}

Beverton R.J.H., 1992, Patterns of reproductive strategy parameters in some marine teleost fishes. J. Fish Biol. 41 (Suppl. B), 137-160.

Beverton R.J.H., Holt S.J., 1956, A review of methods for estimating mortality rates in fish populations, with special reference to sources of bias in catch sampling. Rapp. P.-V. Réun. Cons. Int. Explor. Mer 140, 67-83.

Froese R., Binohlan C., 2000, Empirical relationships to estimate asymptotic length, length at first maturity and length at maximum yield per recruit in fishes, with a simple method to evaluate length frequency data. J. Fish Biol. 56, 758-773.

Fry G.C., Griffiths S.P., 2010, Population dynamics and stock status of cobia, Rachycentron canadum, caught in Australian recreational and commercial coastal fisheries. Fish. Manage. Ecol. 17, 231-239.

González-Armas R., Klett-Traulsen A., Hernández-Herrera A., 2006, Evidence of billfish reproduction in the southern Gulf of California, Mexico. Bull. Mar. Sci. 79, 705-717.

Graves J.E., McDowell J.R., 2003, Stock structure of the world's istiophorid billfishes: a genetic perspective. Mar. Freshw. Res. 54, 287-298.

Hill K.T., Cailliet G.M., Radtke R.L., 1989, A comparative analysis of growth zones in four calcified structures of Pacific blue marlin, Makaira nigricans. Fish. Bull. 87, 829-843.

Hinton M.G., 2001, Status of blue marlin in the Pacific Ocean. Stock Assessment Report 1, Inter-American Tropical Tuna Commission, La Jolla, CA, pp. 284-319.

Hufnagl M., Temming A., Siegel V., Tulp I., Bolle L., 2010, Estimating total mortality and asymptotic length of Crangon crangon between 1955 and 2006. ICES J. Mar. Sci. 67, 875-884.

Jensen A.L., 1996, Beverton and Holt life history invariants result from optimal trade-off of reproduction and survival. Can. J. Fish. Aquat. Sci. 53, 820-822.

Kleiber P., Hinton M.G., Uozumi Y., 2003, Stock assessment of blue marlin (Makaira nigricans) in the Pacific using MUNTIFAN-CL. Mar. Freshw. Res. 54, 349-360.

Kopf R.K., Drew K., Humphreys R.L., 2010, Age estimation of billfishes (Kajikia spp.) using fin spine cross-sections: the need for an international code of practice. Aquat. Living Resour. 23, 13-23.

Molony B., 2008, Fisheries biology and ecology of highly migratory species that commonly interact with industrialised longline and purse-seine fisheries in the western and central Pacific Ocean. Working Paper EB-IP-6, 4th Meeting of the Scientific Committee of the Western and Central Pacific Fisheries Commission (WCPFC-SC4), 11-22 August 2008, Port Moresby, Papua New Guinea.

Nakano H., Matsunaga H., Okamoto H., Okazaki M., 2003, Acoustic tracking of bigeye thresher shark Alopias superciliosus in the eastern Pacific Ocean. Mar. Ecol. Prog. Ser. 265, 255-261.
Ottersen G., Hjermann D., Stenseth N.C., 2006, Changes in spawning stock structure strengthen the link between climate and recruitment in a heavily fished cod (Gadus morhua) stock. Fish. Oceanogr. 15, 230-243.

Patterson K., 1992, Fisheries for small pelagic species: an empirical approach to management targets. Rev. Fish Biol. Fish. 2, 321338.

Pauly D., 1980, On the interrelationships between natural morality, growth parameters and mean environmental temperatures in 175 fish stocks. J. Cons. Int. Explor. Mer 39, 175-192.

Pauly D., 1983, Length-converted catch curves: a powerful tool for fisheries research in the tropics (Part I). Fishbyte 1, 9-13.

Pine W.E., Martell S.J.D., Jensen O.P., Walters C.J., Kitchell J.F., 2008, Catch-and-release and size limit regulations for blue, white, and striped marlin: the role of postrelease survival in effective policy design. Can. J. Fish. Aquat. Sci. 65, 975-988.

Quinn T.J., Deriso R.B., 1999, Quantitative Fish Dynamics. Oxford, New York.

Rochet M.J., Trenkel V.M., 2003, Which community indicators can measure the impact of fishing? A review and proposals. Can. J. Fish. Aquat. Sci. 60, 86-99.

Schaefer K.M., 1996, Spawning time, frequency, and batch fecundity of yellowfin tuna, Thunnus albacares, near Clipperton Atoll in the eastern Pacific Ocean. Fish. Bull. 94, 98-112.

Skillman R.A., Yong M.Y.Y., 1976, Von Bertalanffy growth curves for striped marlin, Tetrapturus audax, and blue marlin, Makaira nigricans, in the central North Pacific Ocean. Fish. Bull. 74, 55366.

Shannon C.E., 1948, A mathematical theory of communication. Bell System Tech. J. 27, 379-423.

Shimose T., Yokawa K., Saito H., Tachihara K., 2012, Sexual difference in the migration pattern of blue marlin, Makaira nigricans, related to spawning and feeding activities in the western and central North Pacific Ocean. Bull. Mar. Sci. 88, 231-249.

Su N.J., Sun C.L., Punt A.E., Yeh S.Z., DiNardo G., 2011a, Modelling the impacts of environmental variation on the distribution of blue marlin, Makaira nigricans, in the Pacific Ocean. ICES J. Mar. Sci. 68, 1072-1080.

Su N.J., Sun C.L., Punt A.E., Yeh S.Z., DiNardo G., 2011b, Evaluation of a spatially sex-specific assessment method incorporating a habitat preference model for blue marlin (Makaira nigricans) in the Pacific Ocean. Fish. Oceanogr. 20, 415-433.

Su N.J., Sun C.L., Punt A.E., Yeh S.Z., DiNardo G., 2012, Incorporating habitat preference into the stock assessment and management of blue marlin (Makaira nigricans) in the Pacific Ocean. Mar. Freshw. Res. 63, 565-575.

Sun C.L., Ehrhardt N.M., Porch C.E., Yeh S.Z., 2002, Analyses of yield and spawning stock biomass per recruit for the South Atlantic albacore (Thunnus alalunga). Fish. Res. 56, 193-204.

Sun C.L., Chang Y.J., Tszeng C.C., Yeh S.Z., Su N.J., 2009, Reproductive biology of blue marlin (Makaira nigricans) in the western Pacific Ocean. Fish. Bull. 107, 420-432.

Thorson J.T., Prager M.H., 2011, Better catch curves: Incorporating age-specific natural mortality and logistic selectivity. Trans. Am. Fish. Soc. 140, 356-366.

Wang S.P., Sun C.L., Yeh S.Z., Chiang W.C., Su N.J., Chang Y.J., Liu C.H., 2006, Length distributions, weight-length relationships, and sex ratios at lengths for the billfishes in Taiwan waters. Bull. Mar. Sci. 79, 865-869.

Wilson C.A., Dean J.M., Prince E.D., Lee D.W., 1991, An examination of sexual dimorphism in Atlantic and Pacific blue marlin using body weight, sagittae weight, and age estimates. J. Exp. Mar. Biol. Ecol. 151, 209-225. 